\title{
Role of hysterolaparoscopy in evaluation and management of infertility
}

\author{
Urmila Karya, Neha Singh*, Komal Rastogi
}

Department of Obstetrics and Gynecology, L. L. R. M. Medical College, Meerut, Uttar Pradesh, India

Received: 04 June 2021

Revised: 26 July 2021

Accepted: 27 July 2021

\section{*Correspondence:}

Dr. Neha Singh,

E-mail: doc.abhi.prakash01@gmail.com

Copyright: (c) the author(s), publisher and licensee Medip Academy. This is an open-access article distributed under the terms of the Creative Commons Attribution Non-Commercial License, which permits unrestricted non-commercial use, distribution, and reproduction in any medium, provided the original work is properly cited.

\section{ABSTRACT}

Background: This study was conducted to evaluate the role of hysteron-laparoscopy in evaluation and management of infertility.

Methods: Prospective observational study was conducted in department of obstetrics and gynaecology, LLRM medical college, SVBP hospital Meerut from May 2019 to June 2020. It included 58 women aged 22-40 years with primary and secondary infertility with normal hormone profile without male factor infertility.

Results: Out of total 58 cases for infertility evaluated, primary infertility were $42(72.41 \%)$ and secondary infertility were $67(27.59 \%)$. In hysteroscopy deep seated ostium (12.06\%), followed by endometrial polyp (6.89\%), intrauterine synechiae $(6.89 \%)$ were the most common pathologies while common abnormalities in laparoscopy were tubal pathology (20.68\%), endometriosis (15.51\%), and PCOD (12.06\%) .Some of the diagnosed pathologies were dealt surgically in same sitting.

Conclusions: Hystero-laparoscopy is a feasible and acceptable procedure and it can be used as "one time approach" in the assessment of female infertility caused due to pelvic and uterine pathology. It helps in diagnosis of certain factors causing infertility, which cannot be diagnosed by any other method such as by USG, HSG and reveals whether surgery is possible and if so the nature of surgery most suited for patient which can be performed in the same sitting.

Keywords: Hysterescopy, Laparoscopy, Infertility

\section{INTRODUCTION}

Infertility is defined by $\mathrm{WHO}$ as a disease of the reproductive system defined by failure to achieve a clinical pregnancy after 12 months or more of regular unprotected intercourse. ${ }^{1}$ Globally between 50 and 80 million couples at some point in their reproductive lives suffer from infertility problems. $^{2}$ It is estimated that around 13-19 million couples are expected to be infertile in India at a given time. ${ }^{3}$ Leading cause of infertility includes tubo-peritoneal disease (40-50\%), ovulatory disorders $(30-40 \%)$, uterine factors $(15-20 \%)$, and male infertility $(30-40 \%))^{4,5}$ The infertility evaluation is designed to isolate and test the integrity of each component insofar as that is possible, and to identify any abnormalities that might impair or prevent conception. The ability to visualize the pelvic cavity, identify peritoneal factors, tubal morphology, patency, ovarian size ,morphology, its relationship to the tubes, uterine size, shape, and pathology through a laparoscope makes its use invaluable. Similarly, using a hysteroscope to had made hysteroscopy an essential part of infertility evaluation. ${ }^{6}$ Hysterosalpingography and laparoscopy are two classical methods to evaluate tubal factors and are complementary to each other rather than mutually exclusive. It provides both panoramic view of pelvic reproductive anatomy and a magnified view of uterine, ovarian, tubal and peritoneal surfaces and its pathology. It 
can confirm a clinical impression, establish a definitive diagnosis, follow the course of disease and modify therapy. ${ }^{7}$

Many of leading factors of infertility are missed by the basic diagnostic procedures like semen analysis, follicular study, hysterosalpingography, ultrasonography and laparoscopy. In reality these methods fail to evaluate the inside of the uterine cavity adequately. At this juncture hysteroscopy as a diagnostic and therapeutic modality is gaining popularity. It has got several advantages like wider availability, acceptability, safety and most importantly its ability to directly visualize the inside of the uterine cavity. ${ }^{8}$ The question of tubal morphology and patency, ovarian morphology, any unsuspected pelvic pathology and uterine cavity abnormalities can all be revealed with accuracy at one session. ${ }^{9}$ Additionally hysteroscopy guided biopsy and definitive surgical procedures like polypectomy, myomectomy, septal resection, ovarian drilling, ovarian cystectomy, adhesiolysis and release of uterine synechiae can be combined together with hysterolaproscopy. ${ }^{10}$ Hence hystero-laparoscopy has proved to be more cost effective and is associated with higher pregnancy rates after treatment.

\section{METHODS}

This study will be conducted in the department of obstetrics and gynaecology, L. L. R. M. medical college, S.V.B.P. hospital Meerut, from May 2019 to June 2020. It is a prospective observational study. 58 infertile women between 22-40 years of age with either primary and secondary infertility will be included in the study. Primary infertility patients are those who have never conceived while secondary infertile patients have at least one prior conception irrespective of outcome. The study included women of age 22-40 years with tubal pathology on HSG, persistentanovulatory cycles, abnormal USG findings and patients with unexplained infertility for 1 year. Women with acute PID, male factor and previous multiple surgeries.Informed consent was taken. After workup and investigations, Pre-anaesthetic checkup and informed consent will be done and patients will be taken up for hysterelaparoscopy in early follicular phase of menstrual cycle under general anaesthesia. Hysteroscopy will be done. This will provide direct view of endometrial cavity and tubal ostia.

Then laparoscopy will be done which involves evaluation of tuboperitoneal factors that is adhesions, tubal mobility with respect to ovary, condition of pouch of Douglas, condition of fimbriaeetc and allows a search to be made for an early stage of endometriosis. Laparoscopic chromopertubation will be carried out by introducing 10 $15 \mathrm{ml}$ of $0.5 \%$ autoclaved methylene blue dye into the uterus using a Neech Wilkinson's cannula and spillage from fimbrial ends will be noted. Whenever required, interventions will be performed in same sitting. Statistical analysis was done using SPSS software version
25. The continuous variables will be expressed as mean \pm SD and categorical variables as proportions. The Student's t-test will be used for comparison of continuous variables and Chi-square test for proportions.

\section{RESULTS}

Out of 58 women $72 \%$ women had primary infertility and rest had secondary infertility. Most of the patients in the study belonged to the 25-30 years age category (8, $65.52 \%)$. Only 9 patients in the study had age greater than 30 years $(9,15.52 \%)$. Multiple abnormalities were detected, laparoscopically in $40(68.9 \%)$ women and hysteroscopically in $22(37.93 \%)$ women. Tubal blockage and endometriosis were the most common abnormality detected in primary infertility and secondary infertility groups respectively. The most common intrauterine pathology in both groups was deep seated ostium followed by polyps as most common pathology in primary infertility and synechiae in secondary infertility. Demographic findings suggested that most of the women were of 25-30 years with primary infertility.

Hysteroscopic findings analysis revealed pale endometrium and endometritis are the common findings in uterus. Polyp was the commonest finding with synechiae and cervical stenosis suggestive of tuberculosis. Laparoscopic findings analysis revealed suggestive of PID such as congestion of tubes, hydrosalpinx, adhesions and tubo-ovarian mass are found. Caseoustubercles were the commonest finding in uterus. Uterine abnormality was also seen in two women in form of subseptate uterus. Large bulky ovaries suggestive of PCOS are the commonest finding followed by peritoneal adhesions either due to PID or endometriosis. Various therapeutic procedures were also done in same sitting for patients.

Table 1: Age wise distribution of the study population.

\begin{tabular}{|lll|}
\hline Age (years) & $\mathbf{N}$ & $\%$ \\
\hline Less than 25 & 11 & 18.96 \\
\hline 25 to 30 & 38 & 65.52 \\
\hline More than 30 & 9 & 15.52 \\
\hline Grand total & 58 & 100.00 \\
\hline
\end{tabular}

Table 2: Status of infertility.

\begin{tabular}{|lll|}
\hline Status of infertility & N & $\%$ \\
\hline Primary & 42 & 72.41 \\
\hline Secondary & 16 & 27.59 \\
\hline Grand total & 58 & 100.00 \\
\hline
\end{tabular}

Table 3: Status of bilateral ostia.

\begin{tabular}{|lll|}
\hline Status of bilateral ostia & N & $\%$ \\
\hline Absent & 50 & 86.21 \\
\hline Present & 8 & 13.39 \\
\hline Grand total & 58 & 100 \\
\hline
\end{tabular}


Table 4: Endometrial status/uterine findings on hysteroscopy.

\begin{tabular}{|lll|}
\hline Endometrium status/ & $\mathrm{N}$ & $\%$ \\
Uterine findings on hysteroscopy & 50 & 86.21 \\
\hline Normal Endometrium & 3 & 5.17 \\
\hline Pale & 3 & 5.17 \\
\hline Congested/endometritis & 1 & 1.72 \\
\hline Submucous myoma & 1 & 1.72 \\
\hline Hyperplastic endometrium & 58 & 100.00 \\
\hline Grand total & & \\
\hline
\end{tabular}

Table 5: Uterine cavity status on hysteroscopy.

\begin{tabular}{|lll|}
\hline $\begin{array}{l}\text { Uterine cavity findings on } \\
\text { hysteroscopy }\end{array}$ & N & $\%$ \\
\hline Normal Cavity & 43 & 74.13 \\
\hline Polyp & 4 & 6.89 \\
\hline Synechiae & 4 & 6.89 \\
\hline Cervical stenosis & 4 & 6.89 \\
\hline $\begin{array}{l}\text { Membranous } \\
\text { septum/fundus/subseptate }\end{array}$ & 2 & 3.45 \\
\hline Small uterine cavity & 1 & 1.72 \\
\hline Grand total & 58 & 100.00 \\
\hline
\end{tabular}

Table 6: Status of bilateral fallopian tubes on laparoscopy.

\begin{tabular}{|lll|}
\hline $\begin{array}{l}\text { Status of bilateral tubes on } \\
\text { laparoscopy }\end{array}$ & N & $\%$ \\
\hline No abnormality detected & 47 & 81.03 \\
\hline Peri tubal adhesions & 4 & 6.90 \\
\hline $\begin{array}{l}\text { B/L Block with fimbrial } \\
\text { Granuloma }\end{array}$ & 2 & 3.44 \\
\hline Congested & 2 & 3.44 \\
\hline Beaded appearance & 1 & 1.72 \\
\hline Hydrosalpinx & 1 & 1.72 \\
\hline Tubo-ovarian mass & 1 & 1.72 \\
\hline Grand total & 58 & 100.00 \\
\hline
\end{tabular}

\section{DISCUSSION}

Infertility is defined as failure to achieve pregnancy within a year of regular unprotected intercourse. Infertile women undergo a series of procedures like HSG, receiving treatment for timing ovulation with coitus, controlled ovulation stimulation with follicular tracing by transvaginal ultrasound, before hysteroscopy and laparoscopy before being referred for ART. Performing hysterolaparoscopy as a single step procedure straightway in these patients proves to be more fruitful as therapeutic interventions or early decisions for ART or both can be undertaken simultaneously.

Hysteroscopy is an important modality to detect uterine anomalies with endometrial pathologies. In the present study bilateral ostia was seen either deep seated or obliterated in $13.74 \%$ women and normal in 50 women. $50(86.21 \%)$ women out of 58 had normal looking endometrium, $5.17 \%$ women had pale endometrium, $5.17 \%$ patients had congested and hyperamic endometrium while hyperplastic endometrium and submucous myoma was seen in $1.72 \%$ of cases each (Table 4).

Table 7: Status of uterus on laparoscopy.

\begin{tabular}{|lll|}
\hline Status of uterus on laparoscopy & $\mathbf{N}$ & $\%$ \\
\hline No abnormality detected & 49 & 84.48 \\
\hline Caseous tubercle & 3 & 5.17 \\
\hline Endometriotic patches & 1 & 1.72 \\
\hline Broad fundus & 2 & 3.44 \\
\hline Myoma & 2 & 3.44 \\
\hline Congested/Hyperaemia & 1 & 1.72 \\
\hline Grand total & 58 & 100.00 \\
\hline
\end{tabular}

Table 8: Status of ovaries on laparoscopy.

\begin{tabular}{|lll|}
\hline Status of ovaries on Laparoscopy & N & $\%$ \\
\hline Normal & 42 & 70.69 \\
\hline Large bulky & 7 & 8.62 \\
\hline Endometriotic cyst & 4 & 3.45 \\
\hline Not seen due to adhesions & 4 & 3.45 \\
\hline Simple/Complex ovarian cyst & 1 & 1.72 \\
\hline Grand Total & 58 & 100.00 \\
\hline
\end{tabular}

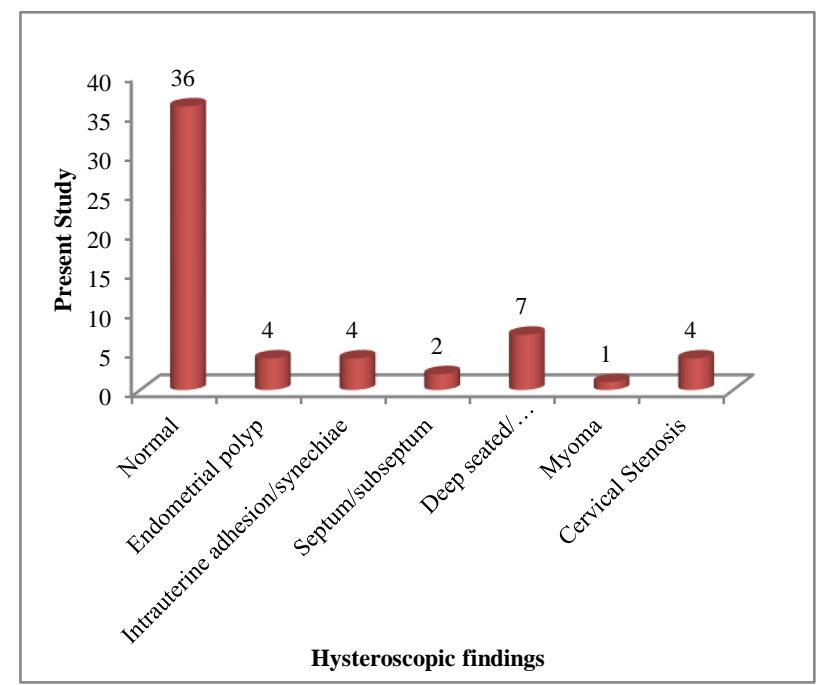

Figure 1: Hysterioscopic findings.

Uterine cavity was normal in $74 \%$ women, fleshy polyp was seen in $6.89 \%$ (Table 5) where hysteroscopic polypectomy was done. Uterine synechiae with irregular cavity was seen in $6.89 \%$ patients, cervical stenosis was seen in $6.89 \%$ patient suggestive of tuberculosis. In our study fleshy polyp and synechiae were most common findings (Figure 1) whereas in study of Kabadi et al uterine anomaly were more common. ${ }^{10}$ Diagnostic laparoscopy is the standard means of diagnosing tubal 
pathology, peritoneal factors, endometriosis and intraabdominal causes of infertility. Laparoscopy often reveals pelvic pathology as endometriosis, PCOS, pelvic

Table 10: Treatment pattern analysis.

\begin{tabular}{|l|l|}
\hline Management & Present study \\
\hline PCO drilling & 5 \\
\hline D\&C, polypectomy & 4 \\
\hline Ovarian cystectomy & 1 \\
\hline Laparoscopic adhesiolysis & 5 \\
\hline Fulgration of endometriotic cyst & 2 \\
\hline ATT course & 5 \\
\hline Antibiotic course & 3 \\
\hline
\end{tabular}

Forty seven $(81.03 \%)$ had normal looking bilateral fallopian tubes. Pathologic findings included peritubal adhesions $(6.90 \%)$ due to PID or abdominal tuberculosis, congested and hyperemic tubes were seen in 2 patients, hydrosalpinx,tubo-ovarian mass due to PID, and beaded appearance of tubes was seen in $1.72 \%$ of cases (Table 6). Out of these 5 patients were started on ATT based on laparoscopic findings. In study done by Madhuri et al tubal pathology was found in 12 patients, $19.7 \%$ patients had tubal pathology in study done by Saumya. ${ }^{11,12}$ Tubal findings in these studies were similar to our study where $19 \%$ of patients had tubal pathology.

In the present study uterine shape and size was normal in $49(84.48 \%)$ cases, caseous tubercles were seen in 3 $(5.17 \%)$ women and endometriotic patches were seen in 1 patient, subserosal to intramural myoma in $2(3.44 \%)$ and congested and hyperemic uterus was seen in 1 women and periadnexal adhesions which may be the major cause of infertility, resulting in change of treatment.

(Table 7). Two patients had were seen to have broad fundus on laparoscopy. Ovaries were normal in 41 patients, large and bulky ovaries suggestive of PCOS were seen in 7 (8.62\%) of cases, ovarian drilling was done in 5 patients in the same sitting, endometriotic cyst was seen in 4 patients, out of which 2 patients had cyst $<3 \mathrm{~cm}$ so endometrioma drainage with fulgration of cyst wall was done in 2 patients . Ovaries could not be visualised in $4(3.45 \%)$ (Table 8$)$. Simple ovarian cyst was seen in one women where cystectomy was done. In the present study on laparoscopy, tubal pathology was seen in 12 patients, ovarian pathology was seen in 7 patients. Endometriosis was seen in 9 patients, PID was present in 3 patients while findings suggestive of genital tuberculosis were seen 5 patients which was confirmed by endometrial biopsy which was sent for gene expert. Rest 18 patients had normal study (Figure 2). In another study done by Agrawal et al on laparoscopy, 42 women had normal findings, 22 had tubal blocks, 12 had simple/complex

ovarian cysts, 14 had polycystic ovaries, 10 had PID, 26 had adhesions, 20 had fibroids, 12 had endometriosis and 2 woman had uterine anomalies. ${ }^{12}$ In present study bilateral spillage in peritoneal cavity on chromopertubation was seen in $46(51.72 \%)$ patients. The remaining 12 patients had spillage on only one side or no spillage (Table 9).

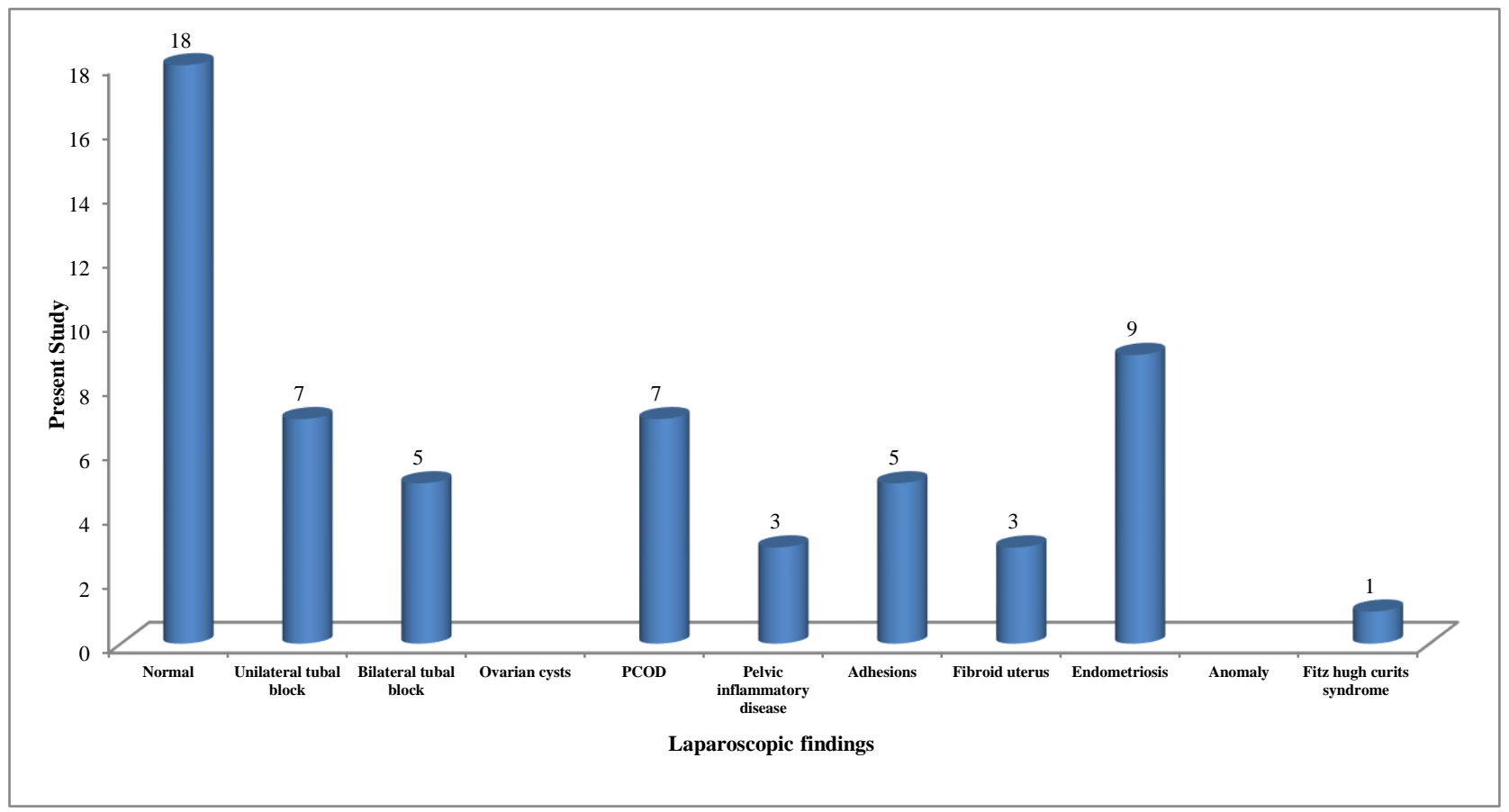

Figure 2: Laparoscopic findings. 
Table 9: Bilateral tube spillage as per infertility status.

\begin{tabular}{|c|c|c|c|c|}
\hline Bilateral tube spillage as per infertility status & Primary & Secondary & Total & P value \\
\hline Absent & $17(40.47)$ & $11(68.75)$ & 28 & \multirow{3}{*}{0.0562} \\
\hline Present & $25(59.52)$ & $5(31.25)$ & 30 & \\
\hline Grand total & 42 & 16 & 58 & \\
\hline
\end{tabular}

\section{Limitations}

Limitations of the study involve that inspite of extensive evaluation with various modalities of testing including hysterolaparoscopy few cases of infertility continue to remain unexplained such as quality of oocytes, abnormalities on fertilization like zona pellucida thickness, poor cumulus, subclinical infections and sperm penetration abnormalities. Post operative period were uneventful for most of patients. Minor post operative pain was only minor complain with mild analgesics. No hemorrhage or infective complications were seen during or after the procedure.

\section{CONCLUSION}

Infertile women with normal ovulatory cycles, seminogram, and hormonal profiles have higher possibility of having tuboperitoneal and subtle endometrial pathologies. These women undergo emotional and financial trauma with anxiety while undergoing series of procedures like HSG, receiving treatment for timing ovulation with coitus, controlled ovulation stimulation with follicular tracing by transvaginal ultrasound, laparoscopy and hysteroscopy over a period of time before being referred to ART. Performing hysterolaparoscopy as a single step procedure straightway has proved in these may be more productive. It has proven to be more fruitful as therapeutic interventions or early decisions for ART hysterolaparoscopy are an excellent diagnostic modality to detect hidden pathology in patients without any overt clinical manifestation. Hence hysterolaparoscopy becomes the "third eye of the gynaecologist" in diagnosing infertility and gives the added advantage of doing a therapeutic procedure in the same sitting.

\section{Funding: No funding sources}

Conflict of interest: None declared

Ethical approval: The study was approved by the Institutional Ethics Committee

\section{REFERENCES}

1. Chanu SM, Rudra Pal GS, Panda S, Santa Singh AS. Diagnostic hysterolaparoscopy for evaluation of infertility: tertiary care hospital. J Hum Reprod Sci. 2018;11:19-23

2. Challenges in reproductive health research: biennial report. Available at: https://apps.who.int/iris/handle/ 10665/39653. Accessed on 20 December 2020.

3. Unisa S. Infertility and treatment seeking in India: Findings from district level household survey. Available at: https://fvvo.eu/assets/133/19-unisa.pdf. Accessed on 20 December 2020.

4. Jahan S. Role of laparoscopy in infertility: review article. Birdem Med J. 2012;2:99-103.

5. Howkins J, Bourine GL. The pathology of conception. In: Howkins J, Bourine GL, eds. Shaw's text book of gynaecology. 13th ed. New York: Elsevier; 2004.

6. Madhuri N, Rashmi HS, Sujatha MS, Dhanyata G. Role of diagnostic hysterolaparoscopy in the evaluation of female infertility. Int $\mathrm{J}$ Contem Med Res. 2010;52:45-9.

7. Cunanan RG, Courey NG, Lippes J. Laparoscopic findings in patients with pelvic pain. Am J Obstet Gynecol. 1983;146(5):589-91.

8. Corfman RS. Indications for hysteroscopy. Obstet Gynecol Clin North Am. 1988;15(1):41-9.

9. Nayak PK, Mahapatra PC, Mallick J, Swain S, Mitra $\mathrm{S}$, Sahoo J. Role of diagnostic hysterolaparoscopy in the evaluation of infertility: A retrospective study of 300patients. J Hum Reprod Sci. 2013;6(1):32-4.

10. Nanaware SS, Saswade M, Shende PN, Gaikwad P, Mahana S, Kirane A. Role of hysterolaparoscopy in the evaluation of female infertility in tertiary care centre. Int J Contem Med Res. 2016;3(10):3063-5.

11. Kabadi YM, Harsha B. Hysterolaparoscopy in the Evaluation and Management of Female Infertility. Am J Obstet Gynecol. 200;52:20:98-105.

12. Agrawal SP, Kedia N, Jani SK. Role of hysterolaparoscopy in the diagnosis and management of infertility. Obstet Gynecol Clin North Am. 2005; 42:25-9.

Cite this article as: Karya U, Singh N, Rastogi K. Role of hysterolaparoscopy in evaluation and management of infertility. Int J Reprod Contracept Obstet Gynecol 2021;10:3413-7 